\title{
THE EFFECT OF HYSTERESIS ON SOIL WATER DYNAMICS DURING SURFACE TRICKLE IRRIGATION IN LAYERED SOILS
}

\author{
ELMALOGLOU S. \\ SOULIS K.X.*
}

\author{
Agricultural University of Athens \\ Department of Natural Resources Management \\ and Agricultural Engineering \\ 75 lera Odos str., 11855 Athens, Greece
}

*to whom all correspondence should be addressed:

\begin{abstract}
In this study, the development of a numerical model simulating surface drip irrigation from equidistant line sources in stratified soils under various conditions is being presented. The developed numerical model was used to investigate the effects of hysteresis, discharge rate, and soil hydraulic properties on soil water dynamics in stratified soils under surface trickle irrigation. Soil water dynamics were simulated for two sequences of soil layers and for two drip lines discharge rates. Soil water distribution patterns, for all conditions examined, were computed first neglecting hysteresis by using the boundary wetting curve only and second considering hysteresis to evaluate the effect of hysteresis on the obtained results. The numerical results showed that hysteresis has a profound effect on the computed soil water distribution patterns and that the draining process progresses more quickly when hysteresis is neglected than when hysteresis is considered. The inclusion of hysteresis results in reduced water losses under the root zone. Moreover, this reduction seems to be more significant in the case that a fine soil is located below a coarse soil. The results also showed that the irrigation efficiency is higher in the same case; however, irrigation efficiency is generally high in all the examined cases of stratified soils.
\end{abstract}

KEYWORDS: drip irrigation, numerical model, hysteresis, stratified soils, irrigation efficiency, deep percolation, equidistant line sources.

\section{INTRODUCTION}

Trickle irrigation represents one of the fastest expanding technologies in modern irrigated agriculture with a great potential for achieving high water use efficiency. Some important considerations in the design of trickle irrigation systems include the percentage of the root zone which should be watered, the spacing of laterals, the application rates, the irrigation dose and the application frequencies necessary to attain the desired coverage.

Several field and laboratory experiments have been conducted to study the moisture distribution patterns under point emitter or line source emitter systems. Most of these experiments conducted on uniform soils. Jury and Earl (1977) studied water movement under different irrigation frequencies. They showed that weekly irrigations resulted in more lateral movement of water than did daily irrigation in a Buren sandy loam (California). Levin et al. (1979) and Mostaghimi et al. (1981) studied the effects of pulsing, which is the application of water in relatively short on-off cycles. Using relatively small application volumes, both studies, showed that pulsing resulted in less vertical movement than continuous application. The major shortcoming of site specific soil moisture distribution experimental studies, is that they cannot be directly applied to the design of trickle irrigation systems for soil other than those tested. Furthermore, only a finite number of application rates and amounts may be tested. For these reasons, both analytical and numerical methods are used to solve the unsaturated flow equations. The equations describing the unsteady multidimensional flow of water in unsaturated soil have generally been solved analytically when restrictive assumptions are imposed, such as, uniform initial moisture, simplified boundary 
conditions, exponential relationship between the pressure head and the hydraulic conductivity $(K)$, and finally the assumption $d K / d \theta=k$, where $k$ is a constant and $\theta$ is the water content.

Several computer models have been developed to predict soil moisture distribution under trickle irrigation (Brandt et al., 1971; Lafolie et al., 1989, Hammami et al., 2002). Many of these have been validated by field and laboratory testing in homogeneous soils (Bresler et al., 1971; Levin et al., 1979). In contrast to the relatively large number of models disregarding plant water uptake, fewer research efforts have been focused on the simulation of trickle irrigation in homogeneous soils considering the water uptake by the plant roots and evaporation from the soil surface (Oron, 1981; Šimůnek et al., 1999; Vrugt et al., 2001; Elmaloglou and Malamos, 2005, 2006) and the phenomenon of hysteresis (Šimůnek et al., 1999; Elmaloglou and Diamantopoulos, 2008). Moreover, even less research of this type has been done in stratified soils under surface or subsurface trickle irrigation (Armstrong and Wilson, 1983; Taghavi et al., 1985; Cote et al., 2003; Li et al., 2007). This lack of information has resulted in inadequate design of most trickle irrigation systems.

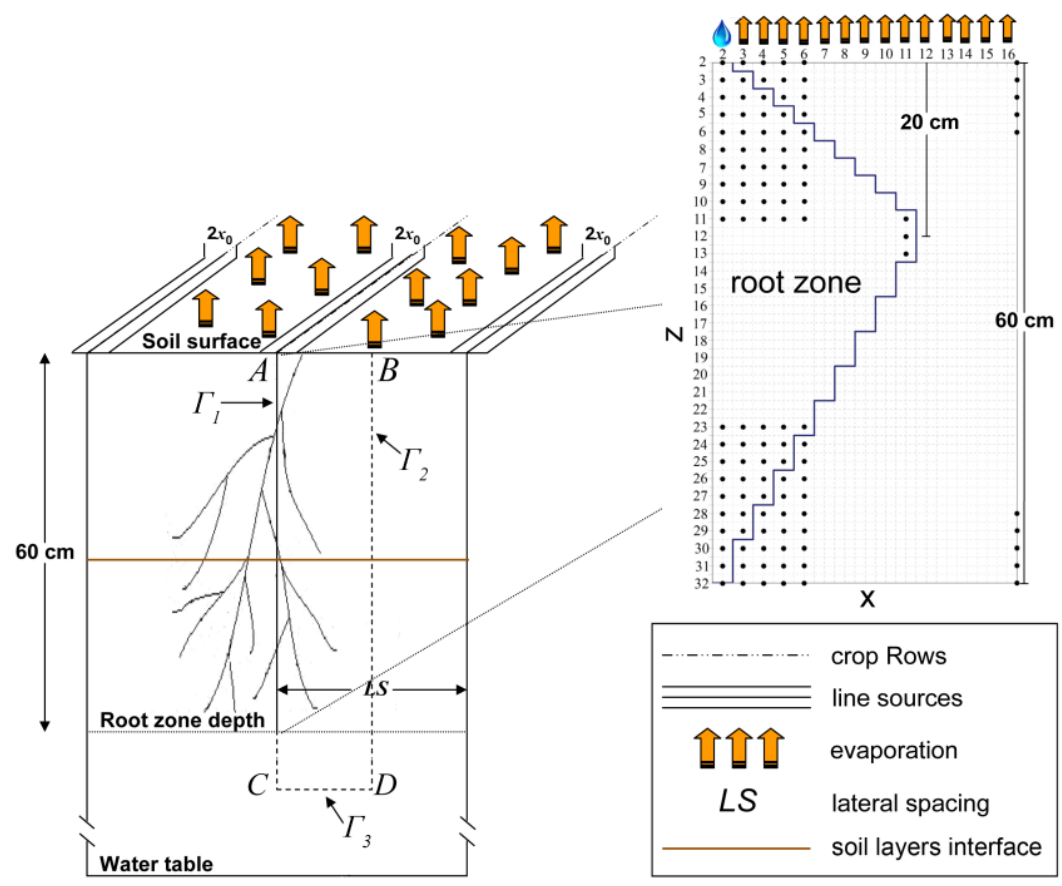

Figure 1. The three dimensional physical model (left) and a graphic display of the active root zone

The objective of this study is the development of a numerical model to investigate the effects of hysteresis, on soil water dynamics in stratified soils under surface trickle irrigation. The effect of hysteresis is investigated in two cases of stratified soils. In the first case the upper layer of the soil profile consist of a coarse loamy sand (LS) soil and the lower layer consist of a fine silty clay loam (SiCL) soil. In the second case the coarse texture (LS) soil lies under the fine texture (SiCL) soil. Finally, for the above cases of stratified soils two drip lines discharge rates $\left(Q=1 \mathrm{I} \mathrm{m}^{-1} \mathrm{~h}^{-1}\right.$ and $\left.2 \mathrm{I} \mathrm{m}^{-1} \mathrm{~h}^{-1}\right)$ are also investigated.

\section{MATERIALS AND METHODS The physical model}

In Fig. 1 a graphical representation of the three-dimensional physical model is illustrated. As it can be seen, surface trickle irrigation is applied from equidistant horizontal line sources, of width $2 x_{0}$. In the same figure, the interface of the two soil layers, the laterals spacing, the crop rows, and the selected two-dimensional distribution of the active root zone, are also shown. The plane flow symmetry allows the physical model to be examined in one of the infinite vertical planes, which are perpendicular to the length of the line sources, and are determined from the $x$ and $z$ axes. Moreover, the discretization of the computational domain is illustrated in Figs. 1 and 2. 


\section{The mathematical model}

The water flow equation that describes the physical problem is:

$$
\frac{\partial \theta}{\partial t}=\frac{\partial}{\partial x}\left(K(H) \frac{\partial H}{\partial x}\right)+\frac{\partial}{\partial z}\left(K(H) \frac{\partial H}{\partial z}\right)-\frac{\partial K(H)}{\partial z}-S(H, z, t)
$$

where $x, z$ are the Cartesian coordinates (L) with $z$ positive downwards, $H$ is the pressure head (L), $K$ is the unsaturated hydraulic conductivity $(\mathrm{L} / \mathrm{T}), \theta$ is the volumetric water content of the soil $\left(\mathrm{L}^{3} / \mathrm{L}^{3}\right), t$ is time since the beginning of flow $(T), S$ is a distributed sink function representing the water uptake by the roots $\left(\mathrm{L}^{3} \mathrm{~L}^{-3} \mathrm{~T}^{-1}\right)$.

\section{Initial and boundary conditions}

The initial condition is:

$$
H(x, z, t=0)=H_{o}(z)
$$

where $H_{o}(z)$ is the initial value of pressure head corresponding to initial volumetric water content $\theta_{o}(z)$ uniform in the horizontal direction. A horizontal water table was imposed at the depth $H_{0}$ and the numerical experiments were begun only when hydrostatic equilibrium had been obtained throughout the flow domain. The boundary condition in the lower right margin of the flow region is defined in such a way that the discretization region is limited to the soil region where the variable $H$ changes with time. The discretization region increases with time as long as the wetting front expands, in such a way that it is restricted between the margins $A B C D$ (Fig. 1). The boundary condition at the moving boundary $\Gamma_{3}$ (Fig. 1) of flow region is:

for $t>0, \quad H=H_{o}(z), \quad$ at $z=Z(t), 0<x<L S / 2$,

where $Z(t)$ is the coordinate of the moving boundary and $L S$ the lateral spacing. The boundary conditions at the constant boundaries of the flow region are:

a) in the plane of symmetry $\Gamma_{2}(x=L S / 2)$, there is a no-flow condition, i.e.:

$$
\text { for } t>0, \quad q_{\mathrm{x}}=-K \frac{\partial H}{\partial x}=0, \quad \text { at } 0 \leq z \leq Z(t)
$$

b) in the plane of symmetry $\Gamma_{1}(x=0)$, there is also a no-flow condition:

for $t>0, \quad q_{\mathrm{x}}=-K \frac{\partial H}{\partial x}=0, \quad$ at $0 \leq z \leq Z(t)$

c) at the soil surface $(z=0)$, the boundary conditions must account for interactions between the applied water rate, evaporation and infiltration into the soil:

for $t>0, \quad q_{0}=\frac{Q}{S_{0}}-E_{a}, \quad$ at $z=0$ and $0<x<X_{0}$

where $Q$ is the line source flow rate $\left(\mathrm{L}^{2} \mathrm{~T}^{-1}\right), E_{a}$ is the actual evaporation rate and $S_{0}=2 x_{0}$.

In general, the initial flux $q_{0}$ is much bigger than $K_{s}$, where $K_{s}$ is the saturated hydraulic conductivity $\left(\mathrm{LT}^{-1}\right)$, so the infiltration zone becomes saturated quickly. Therefore, a fine layer of water is established which expands, symmetrically, around the center of the infiltration zone, if the soil surface is horizontal.

According to the previous analysis, two phases can be discriminated. At the first phase, in which $t<t_{1}$, where $t_{1}$ is the time until the initial infiltration zone is saturated, the condition at the soil surface, assuming there is no rainfall, is:

$$
\begin{array}{ll}
q_{z}=-K \frac{\partial H}{\partial z}+K=\frac{Q}{S_{0}}-E_{a} & \text { at } 0 \leq x \leq X_{0} \\
q_{z}=-K \frac{\partial H}{\partial z}+K=-E_{a} & \text { at } X_{0}<x \leq L S / 2
\end{array}
$$

At the second phase, in which $t \geq t_{1}$, the infiltration zone is saturated. Assuming that the depth of the fine layer of water is negligible, the condition becomes: 
$\begin{array}{ll}H=0 & \text { at } 0 \leq x \leq X_{s}(t) \\ q_{z}=-E_{a} & \text { at } x>X_{s}(t)\end{array}$

$X_{s}(t)$ is defined as the half-width of the infiltration zone. During the first phase $\left(t<t_{1}\right)$, the water balance through the soil surface is obtained with Newman's conditions (Eqs. 7, 8). After the saturation of the infiltration zone $\left(t \geq t_{1}\right)$, the condition of Dirichlet (Eq. 9) does not permit to obtain the water balance maintenance, so it is necessary to impose a new condition that gives, indirectly, the size of the infiltration zone $X_{s}(t)$ at every infiltration time:

$Q=2 \int_{0}^{X_{s}(t)} q_{z} d x$

\section{Implementation}

For the numerical solution of the soil water flow equation (Eq. 1), the Alternating Direction Implicit Method (ADI) is used, which requires the completion of two time stages for a total applying cycle. The simulated region is divided into a network of equally spaced grids $(\Delta x=\Delta z=2 \mathrm{~cm})$, where each point is designated by the subscripts $i$ and $j$, referring to the horizontal and vertical direction respectively, as illustrated in Fig. 2 . The symmetry axis $B D$ is inserted between the columns $(i=N R$, $j)$ and $(i=N R+1, \jmath)$. The moving boundary $\Gamma_{3}$ is inserted between the lines $(i, j=M)$ and $(i, j=M+1)$. The interface between the two different soil layers is situated between two successive nodes (Fig. 2).

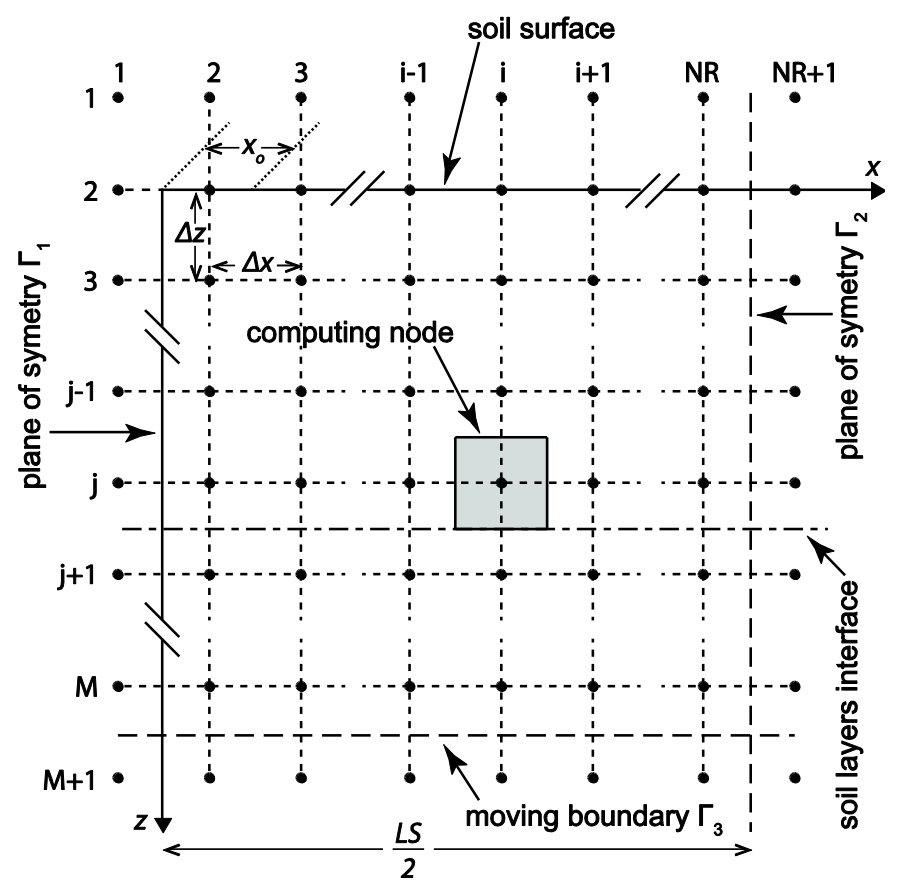

Figure 2. Graphical representation of the discretization of the computational domain

The space-time continuum $(x, z, t)$ is covered by grid points $\left(x_{i}, z_{j}, t^{\ell}\right)$ (Fig. 2), where:

$$
\begin{array}{ll}
x_{i}=(i-1,5) \cdot \Delta x & i=2,3, \ldots, N R+1 \\
z_{j}=(j-2) \cdot \Delta z & j=2,3, \ldots, M+1 \\
t^{\ell}=\sum_{\ell=1}^{\ell} \Delta t^{\ell} & \text { with } t^{\circ}=0
\end{array}
$$

Here, the superscript $\ell$ is used to specify the time level and $\Delta t^{\ell}\left(\Delta t^{\ell}=t^{\ell}-t^{\ell-1}\right)$ is the time step at the $\ell^{\text {th }}$ level of time. In the ADI approach, the solution for the next time level $\left(t^{\ell+1}\right)$ is obtained from 
the known values at the time level $\left(t^{\ell}\right)$ in two stages. During the first stage, the solution is allowed to advance from $t^{\ell}$ to $t^{\ell+1 / 2}$ with implicit differences used in the $z$ - direction and explicit differences in the $x$ - direction, while in the second stage the solution advances from $t^{\ell+1 / 2}$ to $t^{\ell+1}$ with implicit differences in the $x$ - direction and explicit differences in the $z$ - direction. The governing equation (1) is discretized for the first stage as follows:

$$
\begin{aligned}
& \frac{\theta_{i, j}^{\ell+1 / 2, m+1}-\theta_{i, j}^{\ell}}{\Delta t^{\ell} / 2}=\frac{1}{\Delta x}\left(K_{i+1 / 2, j}^{\ell+1 / 2, m} \frac{H_{i+1, j}^{\ell, m+1}-H_{i, j}^{\ell, m+1}}{\Delta x}-K_{i-1 / 2, j}^{\ell+1 / 2, m} \frac{H_{i, j}^{\ell, m+1}-H_{i-1, j}^{\ell, m+1}}{\Delta x}\right) \\
& +\frac{1}{\Delta z}\left(K_{i, j+1 / 2}^{\ell+1 / 2, m} \frac{H_{i, j+1}^{\ell+1 / 2, m+1}-H_{i, j}^{\ell+1 / 2 . m+1}}{\Delta z}-K_{i, j-1 / 2}^{\ell+1 / 2, m} \frac{H_{i, j}^{\ell+1 / 2, m+1}-H_{i, j-1}^{\ell+1 / 2 . m+1}}{\Delta z}\right) \\
& -\frac{K_{i, j+1}^{\ell+1 / 2, m}-K_{i, j-1}^{\ell+1 / 2, m}}{2 \Delta z}-S_{i, j}^{\ell}
\end{aligned}
$$

and for the second stage as:

$$
\begin{aligned}
& \frac{\theta_{i, j}^{\ell+1, m+1}-\theta_{i, j}^{\ell+1 / 2}}{\Delta t^{\ell} / 2}=\frac{1}{\Delta x}\left(K_{i+1 / 2, j}^{\ell+1, m} \frac{H_{i+1, j}^{\ell+1, m+1}-H_{i, j}^{\ell+1 . m+1}}{\Delta x}-K_{i-1 / 2, j}^{\ell+1, m} \frac{H_{i, j}^{\ell+1, m+1}-H_{i-1, j}^{\ell+1 . m+1}}{\Delta x}\right) \\
& +\frac{1}{\Delta z}\left(K_{i, j+1 / 2}^{\ell+1, m} \frac{H_{i, j+1}^{\ell+1 / 2, m+1}-H_{i, j}^{\ell+1 / 2 . m+1}}{\Delta z}-K_{i, j-1 / 2}^{\ell+1, m} \frac{H_{i, j}^{\ell+1 / 2, m+1}-H_{i, j-1}^{\ell+1 / 2 . m+1}}{\Delta z}\right) \\
& -\frac{K_{i, j+1}^{\ell+1, m}-K_{i, j-1}^{\ell+1, m}}{2 \Delta z}-S_{i, j}^{\ell+1 / 2}
\end{aligned}
$$

where $m$ denotes the iteration level. Eqs. (13) and (14) are solved with a Picard iterative solution scheme. It must be also noticed that the sink term, $S$, is evaluated at the previous time level. The masse conservative method by Celia et al., 1990, in which $\theta_{i, j}^{\ell+1 / 2, m+1}$ is expanded in a truncated Taylor series with respect to $H$ about the expansion point $H_{i, j}^{\ell+1 / 2, m}$, is used in the time difference scheme of Eqs. (13) and (14):

$$
\frac{\theta_{i, j}^{\ell+1 / 2, m+1}-\theta_{i, j}^{\ell}}{\Delta t^{\ell} / 2}=C_{i, j}^{\ell+1 / 2, m} \frac{H_{i, j}^{\ell+1 / 2, m+1}-H_{i, j}^{\ell+1 / 2, m}}{\Delta t^{\ell} / 2}+\frac{\theta_{i, j}^{\ell+1 / 2, m}-\theta_{i, j}^{\ell}}{\Delta t^{\ell} / 2}
$$

and

$$
\frac{\theta_{i, j}^{\ell+1, m+1}-\theta_{i, j}^{\ell+1 / 2}}{\Delta t^{\ell} / 2}=C_{i, j}^{\ell+1, m} \frac{H_{i, j}^{\ell+1, m+1}-H_{i, j}^{\ell+1, m}}{\Delta t^{\ell} / 2}+\frac{\theta_{i, j}^{\ell+1, m}-\theta_{i, j}^{\ell+1 / 2}}{\Delta t^{\ell} / 2}
$$

where $C_{i, j}^{\ell+1 / 2, m}=\left.\frac{d \theta}{d H}\right|_{i, j} ^{\ell+1 / 2, m}$ represents the nodal value of the specific moisture capacity function $(1 / L)$. This method has been shown to provide excellent results in terms of minimizing the mass balance error. For the determination of the interlayer hydraulic conductivity for the first stage (vertical seeping) the following modification of the method proposed by Romano et al. (1998) is used. In this modification, the equations (8) and (9) of the Romano et al. (1998 p.318) method were replaced by the following expressions:

$$
K^{-}=\frac{K_{i, j}+\underline{K}_{i, j+1}}{2}, K^{+}=\frac{\underline{K}_{i, j}+K_{i, j+1}}{2}
$$

Due to the lack of analytical solution for the case of stratified soils under trickle irrigation, the only way to control the convergence of the numerical solution is the criterion of maintenance of volume. If $V_{c a l c}^{t}$ is the volume of the water that is stored in the soil profile at time equal to $t, V_{\text {inf }}^{t}$ is the volume of 
water that is infiltrated into the soil, $V_{\text {evap }}$ is the volume of water that is evaporated by the soil surface, and $V_{\text {trans }}$ is the volume of water transpired by the plants in the same time, then the relative volume balance error $(R V B E)$ of the model at time equal to $t$ will be:

$$
R V B E^{t}=\frac{V_{\text {calc }}^{t}+V_{\text {evap }}^{t}+V_{\text {trans }}^{t}-V_{\text {inf }}^{t}}{V_{\text {inf }}^{t}}
$$

In the numerical simulations carried out in this study, the value of the relative volume balance error was about $1 \%$.

\section{Hysteresis and soil physical characteristics}

When water content is monotonically increasing or decreasing (i.e., during infiltration, evaporation, or gravity drainage), the $\theta(H)$ relationship can be described by a single sorption curve representing either a wetting or drying cycle. However, because of periodic changes in irrigation flux or evaporation rate, water content frequently undergoes wetting and drying cycles near the soil surface. In such cases a single $\theta(H)$ curve is not appropriate, and it is necessary to introduce hysteresis into the water flow model (Russo et al., 1989). To facilitate the analysis of the water flow, it is desirable to have an efficient hysteresis model. In this study, the phenomenon of hysteresis in the soil water characteristic curve is incorporated in the mathematical model with the simplification made by Kool and Parker (1987) for the empirical model of Scott et al., (1983). Elmaloglou and Diamantopoulos (2008) explain this method in detail.

Two of the twelve USDA soil classes (Schaap and Leij, 1998) covering a wide range of cultivated soils were selected and the class average values of the $\theta(H)$ and $K(H)$ relationships according to van Genuchten (1980) are used. The analytical expressions of those relationships are:

$$
\begin{aligned}
& \theta(H)=\left\{\begin{array}{l}
\theta_{r}+\frac{\theta_{s}-\theta_{r}}{\left(1+|a H|^{n}\right)^{m}}, H<0 \\
\theta_{s}, H \geq 0
\end{array}\right. \\
& K(H)=K_{s} S e^{0.5}\left[1-\left(1-S e^{n /(n-1)}\right)^{m}\right]^{2}
\end{aligned}
$$

where $S e=\frac{\theta(H)-\theta_{r}}{\theta_{s}-\theta_{r}}, m=1-1 / n$

and $\theta_{r}$ is the residual water content $\left(\mathrm{L}^{3} / \mathrm{L}^{3}\right) ; \theta_{s}$ is the saturated water content $\left(\mathrm{L}^{3} / \mathrm{L}^{3}\right) ; K_{s}$ is the saturated hydraulic conductivity $(\mathrm{L} / \mathrm{T}) ; \mathrm{Se}$ is the effective saturation (dimensionless) and $n(-), a(1 / \mathrm{L})$ are shape parameters. To determine the main drying curve from the main wetting curve, the empirical model introduced by Scott et al. (1983) and modified by Kool and Parker (1987) is used. It is assumed that $a_{d}=a_{w} / 2$, where $a_{w}$ and $a_{d}$ are the values of the $a$ parameter in the relationship of van Genuchten (1980) for the main wetting and the main drying curve. The values of the two soils parameters included in the van Genuchten equations (Eqs. 19 to 21) are summarized in Table 1. The unique $K(\theta)$ relation for each soil always follows from the parameter set $\left(n, \theta_{s}, \theta_{r}, K_{s}\right)$ according to Eqs. (20) and (21) (Kroes and van Dam, 2003).

\section{Simulation inputs}

Two layered soils with different soil layers' sequences and thicknesses are tested. The first layered soil consists of an upper, $31 \mathrm{~cm}$ thick, layer of loamy sand soil and a lower layer of silty clay loam soil, which thickness is greater than $289 \mathrm{~cm}$ (referred to as LS-SiCL) and the second layered soil consisted of an upper, $31 \mathrm{~cm}$ thick, layer of silty clay loam soil and a lower layer of loamy sand soil , which thickness is greater than $302 \mathrm{~cm}$ (referred to as SiCL-LS). The water table is imposed at the depth $H_{0}=320 \mathrm{~cm}$ for the (LS-SiCL) layered soil and at the depth $H_{0}=333 \mathrm{~cm}$ for the (SiCL-LS) respectively. The above values of $H_{0}$ were chosen so that at time $t=0$, the two layered soils had the same value of effective saturation in the active root zone $(S e=0.38)$. 
Table 1. Values of the shape parameter $(n)$, the saturated $\left(\theta_{s}\right)$, residual $\left(\theta_{r}\right)$ water contents, the saturated hydraulic conductivity $\left(K_{s}\right)$ and the scaling factors $\left(\alpha_{w}\right)$ and $\left(\alpha_{d}\right)$ for the main wetting and drying curve, respectively

\begin{tabular}{lcccccc}
\hline Soil & $\begin{array}{c}\alpha_{w} \\
\left(\mathrm{~cm}^{-1}\right)\end{array}$ & $\begin{array}{c}\alpha_{d} \\
\left(\mathrm{~cm}^{-1}\right)\end{array}$ & $\begin{array}{c}n \\
(-)\end{array}$ & $\begin{array}{c}\theta_{s} \\
\left(\mathrm{~cm}^{3} \mathrm{~cm}^{-3}\right)\end{array}$ & $\begin{array}{c}\theta_{r} \\
\left(\mathrm{~cm}^{3} \mathrm{~cm}^{-3}\right)\end{array}$ & $\begin{array}{c}K_{s} \\
\left(\mathrm{~cm} \mathrm{~h}^{-1}\right)\end{array}$ \\
\hline loamy sand & 0.03467 & 0.017335 & 1.7378 & 0.390 & 0.049 & 4.383 \\
silty clay loam & 0.00832 & 0.004160 & 1.5136 & 0.482 & 0.090 & 0.467 \\
\hline
\end{tabular}

The predicted evapotranspiration rate $E T_{p}\left(\mathrm{~mm} \mathrm{~h}^{-1}\right)$, is calculated by distributing the daily potential evapotranspiration $E T_{\text {day }}\left(\mathrm{mm}^{-1} \mathrm{day}^{-1}\right)$ over a $24-\mathrm{h}$ period (Vellidis and Smajstrla, 1992). A sinusoidal type distribution was selected:

$E T_{p}=\frac{E T_{\text {day }}}{T_{\text {cycle }}}\left[1+\sin \left[\frac{2 \pi T_{\text {day }}}{T_{\text {cycle }}}-\frac{\pi}{2}\right]\right]$

where $T_{\text {cycle }}$ is the period of the cycle, (h), in this case $24 \mathrm{~h}$, and $T_{\text {day }}$ is the current time on the 24-h clock, (h). The daily potential evapotranspiration $E T_{\text {day }}$ was chosen to be equal to $8.4 \mathrm{mmday}^{-1}$, which is acceptable for the dry period in semi-arid regions and it was partitioned into daily potential evaporation $E_{p}\left(1.2\right.$ mmday $\left.^{-1}\right)$ and daily potential transpiration $T_{p}\left(7.2 \mathrm{mmday}^{-1}\right)$. Fig. 1 provides a graphic representation of the active root zone. More specifically a two-dimensional distribution of roots is used. The width of the plant root system is minimal on the surface and increases with depth up to $20 \mathrm{~cm}$, where it acquires its maximum width. Then the width is reduced up to $60 \mathrm{~cm}$, which is equal to the root zone depth. The transpiration rate is expressed by the distributed sink term, $\mathrm{S}$, which is a function of maximum water extraction rate $S_{\max }$ at depth $z$ and the water pressure head $H$ (Feddes et al., 1978):

$$
S=a(H) \cdot S_{\max }(z)
$$

where $H=0$ for $H \geq H_{1}=-10 \mathrm{~cm}$ or $H \leq H_{4}=-15000 \mathrm{~cm}, H=\left(H-H_{1}\right) /\left(H_{2}-H_{1}\right)$ for the pressure head $H$ between $H_{1}$ and $H_{2}=-25 \mathrm{~cm}, H=1$ for $H$ ranging between $H_{2}$ and $H_{3}=-400 \mathrm{~cm}$ and $H=$ $\left(H-H_{4}\right) /\left(H_{3}-H_{4}\right)$ for $H_{4}<H<H_{3}$. For the nodes lying outside the active root system, the sink term was set equal to zero. For the nodes lying inside the root system it was assumed that they are all involved in transpiration with the same weight. The mathematical model considers the actual evaporation rate $E_{a}$ from the soil surface as follows:

$$
\begin{array}{lll}
E_{a}=E_{p} & \text { if } & E_{\max }>E_{p} \\
E_{a}=E_{\max } & \text { if } & E_{\max } \leq E_{p}
\end{array}
$$

where $E_{\max }\left(\mathrm{cmd}^{-1}\right)$ is the maximum evaporation rate on the soil surface according to Darcy:

$$
E_{\text {max }}=K_{2, j}\left(\frac{H_{a t m}-H_{2, j}}{\Delta z}-1\right)
$$

where $K_{2, j}\left(\mathrm{cmh}^{-1}\right), H_{2, j}(\mathrm{~cm})$ are the hydraulic conductivity and the soil water pressure head of the soil surface nodes respectively, $\Delta z$ the compartment thickness, and $H_{\text {atm }}(\mathrm{cm})$ the soil water pressure 
in equilibrium with the prevailing air relative humidity $\left(H_{a t m} \approx-2.75 \cdot 10^{5} \mathrm{~cm}\right)$, (Kroes and van Dam, 2003).

\section{RESULTS AND DISCUSSION}

Soil water dynamics were simulated for two sequences of soil layers (LS-SiCL) and (SiCL-LS), for two drip lines discharge rates $\left(Q=1 \mathrm{I} \mathrm{m}^{-1} \mathrm{~h}^{-1}\right.$ and $\left.2 \mathrm{I} \mathrm{m}^{-1} \mathrm{~h}^{-1}\right)$ and for an irrigation depth of $40 \mathrm{~mm}$. The irrigation durations vary according to the discharge rate (Table 2). Two different cases were considered. In the first case, the water content profiles were calculated with hysteresis neglected by using the boundary wetting curve $\theta(H)$ only. In the second case, the profiles were calculated with hysteresis taken into account.

Table 2. Combinations of discharge rate and irrigation durations

\begin{tabular}{ccc}
\hline $\begin{array}{c}\text { Discharge rate } \\
\left(\mathrm{I} \mathrm{m}^{-1} \mathrm{~h}^{-1}\right)\end{array}$ & $\begin{array}{c}\text { Irrigation duration }\left(\mathrm{t}_{\mathrm{i}}\right) \\
(\mathrm{h})\end{array}$ & $\begin{array}{c}\text { Irrigation depth } \\
(\mathrm{mm})\end{array}$ \\
\hline 1 & 24.0 & 40 \\
\hline 2 & 12.0 & 40 \\
\hline
\end{tabular}

In Figs. 3 to 6 , the soil water content profiles for infiltration and redistribution at four different times $(t$ $=0 \mathrm{~h}$, time equal to the irrigation duration $\left(t_{i}\right), t=48 \mathrm{~h}$, and time equal to the total simulation time $\left.\left(t_{\text {end }}\right)\right)$, for three horizontal distances of $1 \mathrm{~cm}, 15 \mathrm{~cm}$, and $29 \mathrm{~cm}$ from the line source respectively, and for all the cases investigated are illustrated. The irrigation duration $\left(t_{i}\right)$ varies according to the line source discharge rate, and it can be calculated from the following equation:

$t_{i}=\frac{\text { irrigation depth } \times \text { line source spacing }}{\text { line source discharge rate }}$

The total simulation time ( $\left.t_{e n d}\right)$ is defined as the time needed for the average water content in the effective root zone (Fig. 1) to reach the initial average water content. The $t_{i}$ and $t_{\text {end }}$ values for each case examined are given in Tables 2 and 3 . In these figures it can be observed that hysteresis has a profound effect on the computed soil water distribution patterns. As it can be clearly seen, when hysteresis is neglected (i.e. the wetting $\theta(H)$ curve is used for both wetting and draining), the redistribution process progresses more quickly than when hysteresis is considered. Specifically, the $\theta(z)$ redistribution profiles shown in Figs 3 to 6 indicate that the maximum $\theta$ values are located in the near surface horizons in the case that hysteresis is included. In contrast, when hysteresis is neglected the maximum $\theta$ values are located at greater depths. These findings are in good agreement with the results presented by Jones and Watson (1987) that simulated one-dimensional infiltration and redistribution without considering root-water uptake and evaporation from the soil surface These findings are also in agreement with the results presented by Elmaloglou and Diamantopoulos (2008) that simulated drip irrigation in homogeneous soils considering root water uptake and evaporation from the soil surface.

A similar observation can be made by analyzing the total simulation times ( $\left.t_{\text {end }}\right)$ presented in Table 3 . As it can be seen hysteresis retards the whole draining procedure. This is more obvious in the case of the LS-SiCL layered soil.

Table 3. The total simulation time (h) for the two cases (without hysteresis, hysteresis considered)

\begin{tabular}{cllll}
\hline \multirow{2}{*}{$\begin{array}{c}\text { Discharge rate } \\
\left(\mathrm{I} \mathrm{m}^{-1} \mathrm{~h}^{-1}\right)\end{array}$} & \multicolumn{2}{l}{ Hysteresis neglected } & \multicolumn{2}{l}{ Hysteresis considered } \\
\cline { 2 - 5 } & LS-SiCL & SiCL-LS & LS-SiCL & SiCL-LS \\
\hline 1 & 102.5 & 106.3 & 106.6 & 107.2 \\
\hline 2 & 101.3 & 105.0 & 105.6 & 106.5 \\
\hline
\end{tabular}


An overview of the obtained results is presented in Table 4. In this table, deep percolation, irrigation efficiency in terms of actual transpiration, and actual evaporation are presented as a percentage of the applied irrigation depth, for the two sequences of soil layers, the two drip lines discharge rates, and for both including and neglecting hysteresis. Irrigation efficiency is defined as the ratio of the average depth of irrigation water that is beneficially used to the average depth of irrigation water applied (Elmaloglou et al., 2013). As it can be seen, the inclusion of hysteresis results in reduced water losses under the root zone. This reduction seems to be more significant in the case of the (LS$\mathrm{SiCL}$ ) layered soil. It can be also seen that for both soil layers sequences and for both drip lines discharge rates, the value of the irrigation efficiency is higher in the case that hysteresis is considered (Table 4). The above results concerning the effect of hysteresis on deep percolation and irrigation efficiency are in agreement with the results of Elmaloglou and Diamantopoulos (2008) for the case of homogeneous soils.

Table 4. Deep percolation, actual transpiration, and actual evaporation as a percentage of the applied irrigation depth

\begin{tabular}{cccccc}
\hline \multirow{2}{*}{\begin{tabular}{c} 
Line sources $\begin{array}{c}\text { spacing } \\
(\mathrm{cm})\end{array}$ \\
\cline { 3 - 6 }
\end{tabular}} & soil type & \multicolumn{4}{c}{$1 \mathrm{I} \mathrm{m}^{-1} \mathrm{~h}^{-1}$} \\
\cline { 3 - 6 } & & $\begin{array}{c}\text { Hysteresis } \\
\text { neglected }\end{array}$ & $\begin{array}{c}\text { Hysteresis } \\
\text { considered } \\
\text { Deep percolation (\%) }\end{array}$ & $\begin{array}{c}\text { Hysteresis } \\
\text { neglected }\end{array}$ & $\begin{array}{c}\text { Hysteresis } \\
\text { considered }\end{array}$ \\
\hline \multirow{2}{*}{60} & LS-SiCL & 3.1 & 0.1 & 4.8 & 1.1 \\
& SiCL-LS & -0.6 & -0.7 & -0.4 & -0.6 \\
\hline \multirow{2}{*}{60} & LS-SiCL & 73.1 & 78.0 & 72.5 & 77.2 \\
& SiCL-LS & 75.3 & 75.4 & 74.9 & 75.1 \\
\hline \multirow{2}{*}{60} & & \multicolumn{5}{c}{ Soil evaporation (\%) } \\
\hline & LS-SiCL & 13.1 & 12.3 & 12.9 & 11.8 \\
& SiCL-LS & 13.3 & 13.1 & 12.9 & 12.6 \\
\hline
\end{tabular}

Finally, it can be observed that the irrigation efficiency is generally higher in the case that the fine soil is located below the coarse soil, at least for the more accurate case that hysteresis is considered. However, irrigation efficiency is generally high in all the examined cases of stratified soils. 

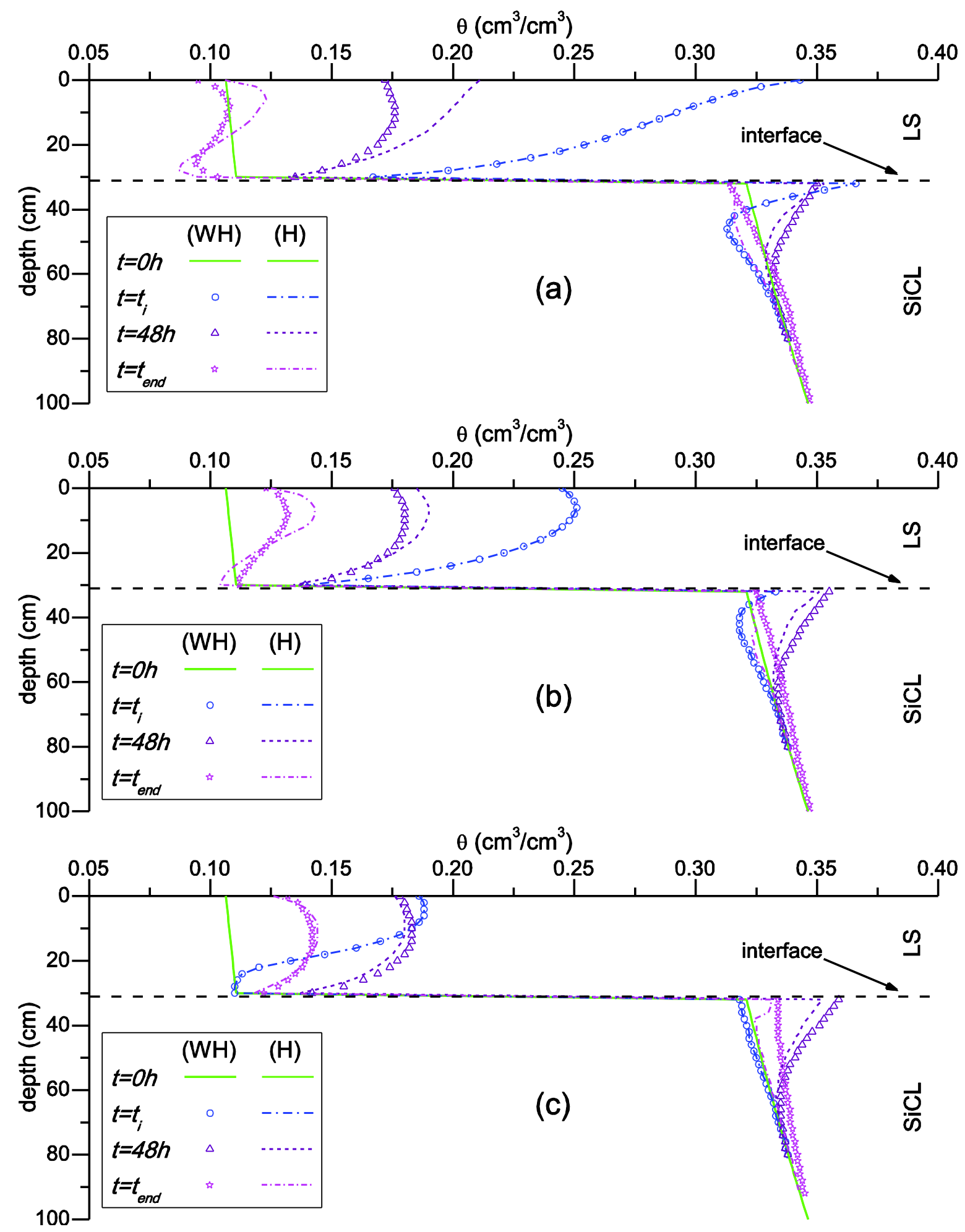

Figure 3. Soil water content profiles for the LS-SiCL layered soil, for $Q=1 \mathrm{I} \mathrm{m}^{-1} \mathrm{~h}^{-1}$, including hysteresis $(\mathrm{H})$ and neglecting hysteresis $(\mathrm{WH})$, for three horizontal distances of (a) $1 \mathrm{~cm}$, (b) $15 \mathrm{~cm}$, and (c) $29 \mathrm{~cm}$ from the line source, at four different times $\left(0 \mathrm{~h}, t_{i}, 48 \mathrm{~h}, t_{e n d}\right)$ 

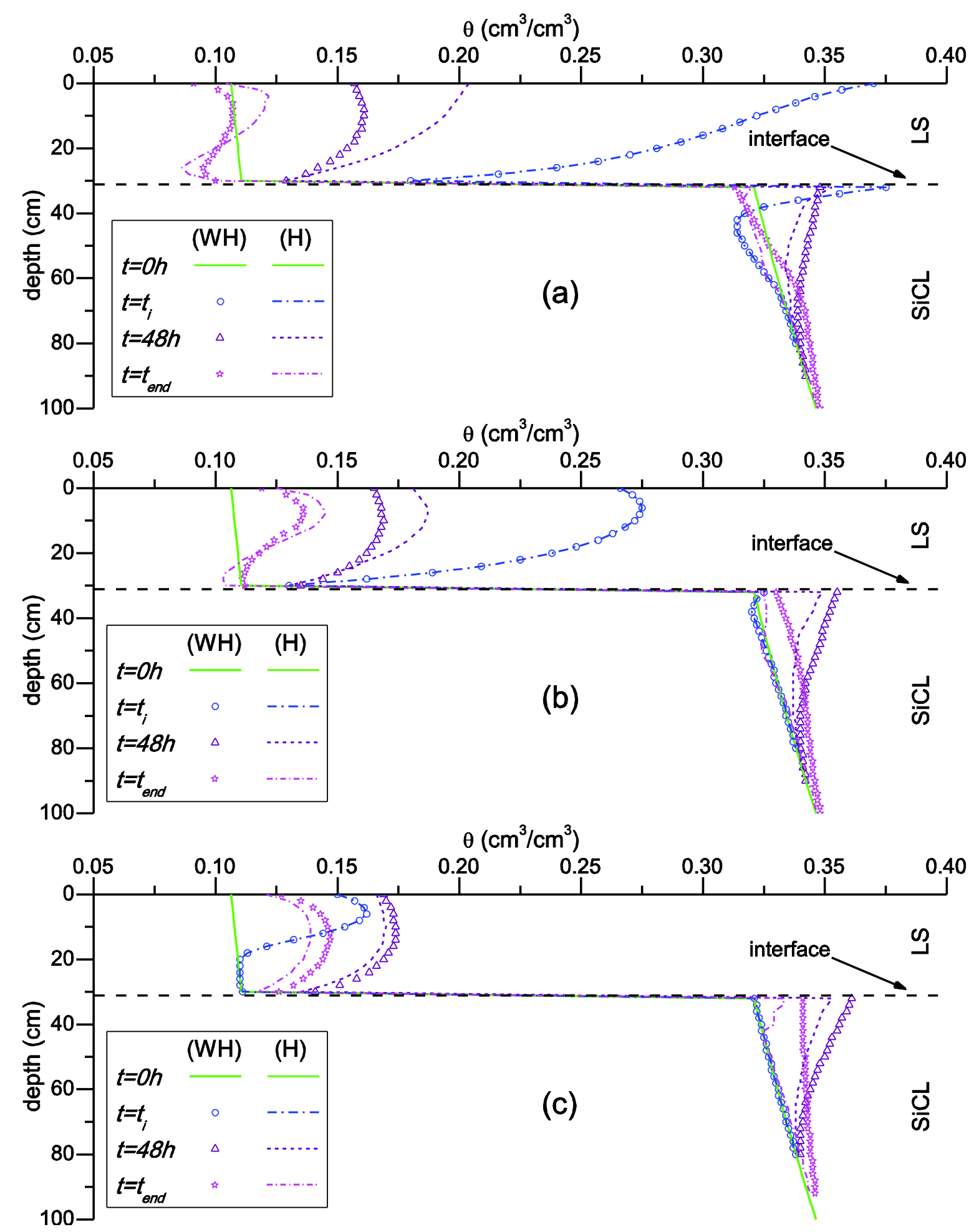

Figure 4. Soil water content profiles for the LS-SiCL layered soil, for $Q=2 \mathrm{I} \mathrm{m}^{-1} \mathrm{~h}^{-1}$, including hysteresis $(\mathrm{H})$ and neglecting hysteresis $(\mathrm{WH})$, for three horizontal distances of (a) $1 \mathrm{~cm}$, (b) $15 \mathrm{~cm}$, and (c) $29 \mathrm{~cm}$ from the line source, at four different times (0h, ti, $\left.48 \mathrm{~h}, t_{\text {end }}\right)$ 

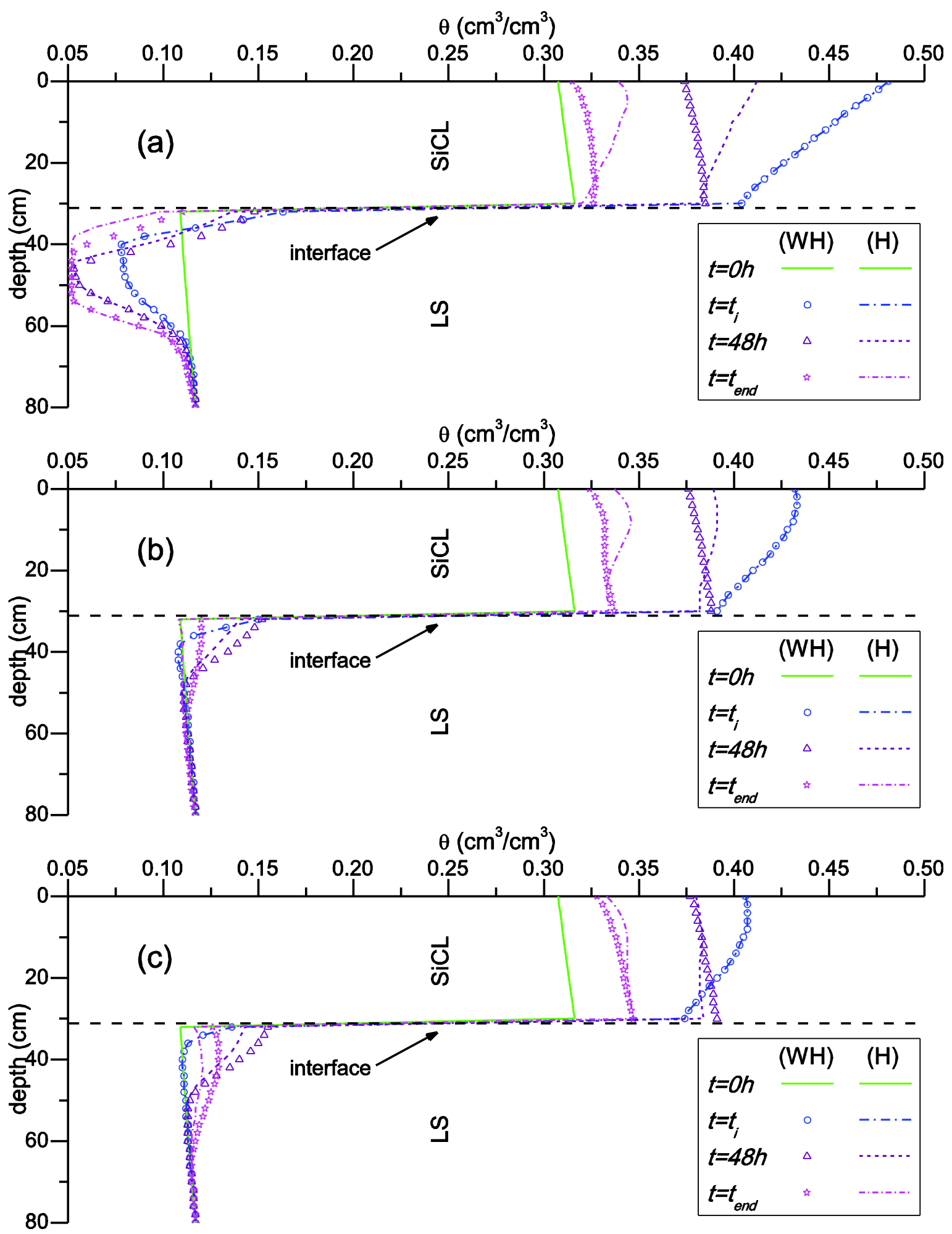

Figure 5. Soil water content profiles for the SiCL-LS layered soil, for $Q=1 \mathrm{I} \mathrm{m}^{-1} \mathrm{~h}^{-1}$, including hysteresis $(\mathrm{H})$ and neglecting hysteresis $(\mathrm{WH})$, for three horizontal distances of (a) $1 \mathrm{~cm}$, (b) $15 \mathrm{~cm}$, and (c) $29 \mathrm{~cm}$ from the line source, at four different times $\left(0 \mathrm{~h}, t_{i}, 48 \mathrm{~h}, t_{\text {end }}\right)$ 

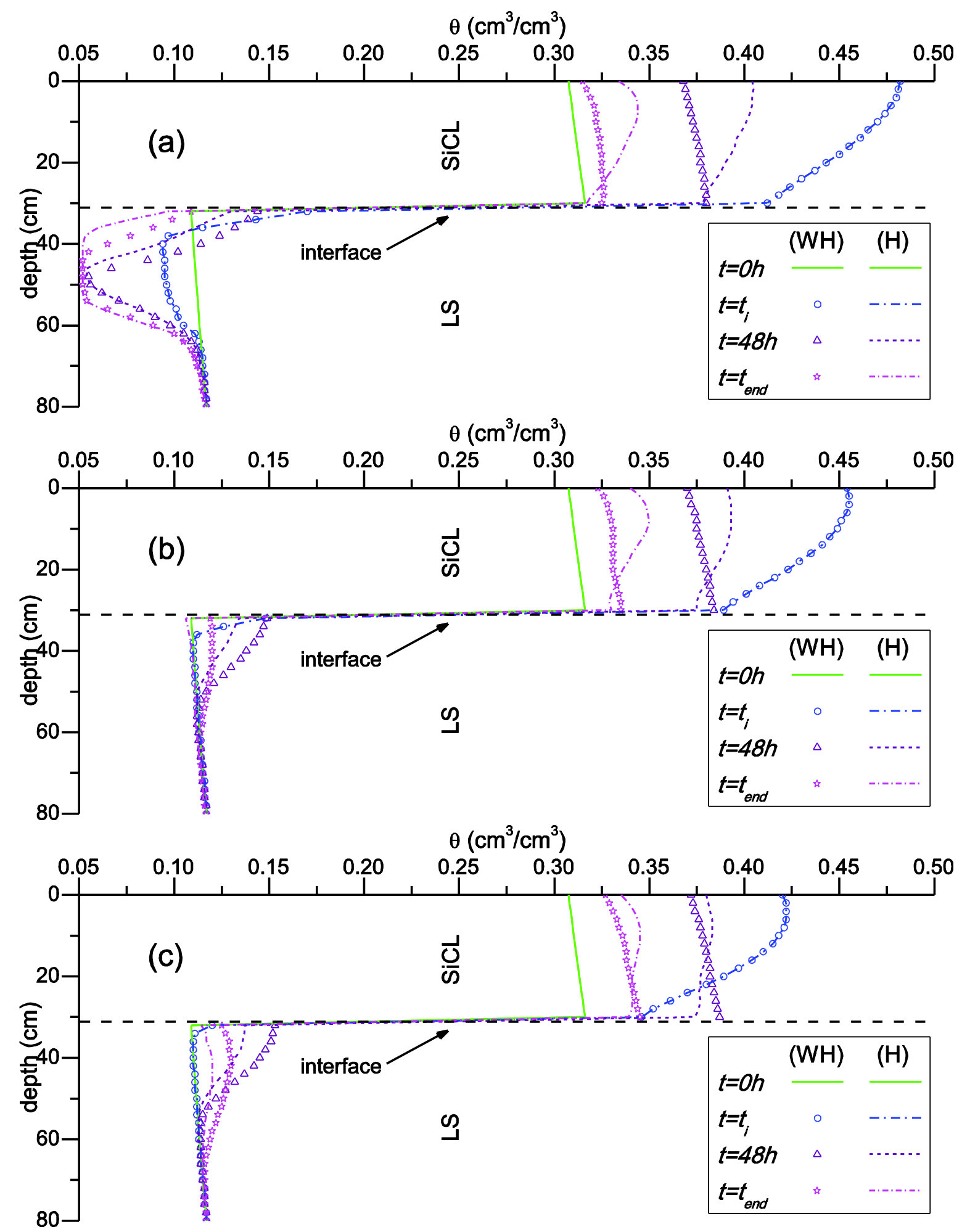

Figure 6. Soil water content profiles for the SiCL-LS layered soil, for $Q=2 \mathrm{I} \mathrm{m}^{-1} \mathrm{~h}^{-1}$, including hysteresis $(\mathrm{H})$ and neglecting hysteresis $(\mathrm{WH})$, for three horizontal distances of (a) $1 \mathrm{~cm}$, (b) $15 \mathrm{~cm}$, and (c) $29 \mathrm{~cm}$ from the line source, at four different times $\left(0 \mathrm{~h}, t_{i}, 48 \mathrm{~h}, t_{\text {end }}\right)$ 


\section{SUMMARY AND CONCLUSIONS}

In this study, a numerical model, which is able to simulate surface drip irrigation from equidistant line sources in stratified soils under various conditions, was developed. This numerical model was used to investigate the effects of hysteresis, on soil water dynamics in stratified soils under surface trickle irrigation. The convergence of the numerical solution was tested with the criterion of maintenance of volume. The value of the relative volume balance error was about $1 \%$ in all the numerical simulations carried out. The effect of hysteresis was investigated for two sequences of soil layers (LS-SiCL and SiCL-LS) and for two drip lines discharge rates $\left(Q=1 \mathrm{I} \mathrm{m}^{-1} \mathrm{~h}^{-1}\right.$ and $\left.2 \mathrm{I} \mathrm{m}^{-1} \mathrm{~h}^{-1}\right)$.

The numerical results showed that the redistribution process progress more quickly when hysteresis was neglected than when hysteresis was considered. The inclusion of hysteresis resulted in reduced water losses under the root zone and in increased irrigation efficiency. Moreover, this reduction seems to be more significant in the case of the LS-SiCL layered soil. The results also showed that the irrigation efficiency is higher in the case that the fine soil is located below the coarse soil; however, irrigation efficiency is generally high in all the examined cases of stratified soils.

According to the obtained results it can be concluded that hysteresis significantly influences the computation of soil water distribution patterns in the case of surface drip irrigation from equidistant line sources in stratified soils. Therefore, hysteresis should be considered in order to achieve adequate results in similar studies.

\section{REFERENCES}

Armstrong C.F. and Wilson T.V. (1983) Computer model for moisture distribution in stratified soils under trickle source, Trans. ASAE, 26, 1704-1709.

Bresler E., Heller J., Diner N., Ben-Asher J., Brandt A. and Goldberg D. (1971) Infiltration from a trickle source, 2. Experimental data and theoretical predictions, Soil Sci. Soc. Am. Proc., 35(5), 683-689.

Celia M.A., Bouloutas E.T. and Zarba R.L. (1990) A general mass-conservative numerical solution for the unsaturated flow equation, Water Resour. Res., 26, 1483-1496.

Cote C.M., Bristow K.L., Charlesworth P.B., Cook F.J. and Thorburn P.J., (2003) Analysis of soil wetting and solute transport in subsurface trickle irrigation, Irrig. Sci., 22, 143-156.

Elmaloglou S. and Diamantopoulos E. (2008) The effect of hysteresis on three-dimensional transient water flow during surface trickle irrigation, Irrig. Drain., 57(1), 57-70.

Elmaloglou S. and Malamos N. (2005) Estimation of the wetted soil volume depth, under a surface trickle line source, considering evaporation and water extraction by roots, Irrig. Drain. 54, 417-430.

Elmaloglou S. and Malamos N., (2006) A methodology for determining the surface and vertical components of the wetting front under a surface point source, with root water-uptake and evaporation, Irrig. Drain., 55(1), 99-111.

Elmaloglou S., Soulis K.X. and Dercas, N. (2013) Simulation of soil water dynamics under surface drip irrigation from equidistant line sources, Water Resour. Manage., in press, DOI 10.1007/s11269013-0399-8.

Hammami M., Daghari H., Balti J. and Maalej M. (2002) Approach for predicting the wetting front depth beneath a surface point source: theory and numerical aspect, Irrig. Drain., 51, 347-360.

Jones M.J. and Watson K.K. (1987) Effect of soil water hysteresis on solute movement during intermittent leaching, Water Resour. Res., 23(7), 1251-1256.

Jury W.A. and Earl K.D. (1977) Water movement in bare and cropped soil under isolated trickle emitters. 1. Analysis of bare soil experiments, Soil Sci. Soc. Am. J., 41(5), 852-856.

Kool J.B. and Parker J.C. (1987) Development and evaluation of closed-from expressions for hysteretic soil hydraulic properties, Water Resour. Res., 23(1), 105-114.

Kroes J.G. and van Dam J.C. (eds), (2003) Reference Manual SWAP version 3.0.3. Alterra-report 773, $211 \mathrm{pp}$, Alterra, Research Institute, Wageningen, The Netherlands.

Lafolie F., Guennelon R. and Van Genuchten M.T. (1989) Analysis of water flow under trickle-irrigation. 1: Theory and numerical solution, Soil Sci. Soc. Am. J., 53(5), 1310-1318.

Levin I., van Royen P.C. and van Royen F.C. (1979) The effect of discharge rate and intermittent water application by point-source irrigation on the soil moisture distribution pattern, Soil Sci. Soc. Am. J., 43, 8-16.

Li J., Ji H., Li B. and Liu Y. (2007) Wetting patters and nitrate distribution in layered-textual soils under drip irrigation, Agric. Sci. China, 6, 970-980.

Mostaghimi S., Mitchel J.K. and Lembke W.D. (1981) Effect of pulsed trickling on moisture distribution patterns in heavy soils, ASAE Paper No. 81-2553. 
Oron G. (1981) Simulation of water flow in the soil under sub-surface trickle irrigation with water uptake by roots, Agric. Water Manage., 3, 179-193.

Romano N., Brunone B. and Santini A. (1998) Numerical analysis of one-dimensional unsaturated flow in layered soils, Adv. Water Resour., 21, 315-324.

Schaap M.G. and Leij L.J. (1998) Database-related accuracy and uncertainty of pedotransfer functions, Soil Sci., 163, 765-779.

Scott P.S., Farquhar G.J. and Kouwen N. (1983) Hysteretic effects on net infiltration. In Advances in infiltration, ASCE Publication 11-83, St. Joseph, Mich. pp. 163-170.

Šimůnek J., Šejna M. and van Genuchten M.T. (1999) The HYDRUS-2D software package for simulating two-dimensional movement of water, heat, and multiple solutes in variable saturated media. Version 2.0, IGWMC-TPS-53, International Ground Water Modeling Center, Colorado School of Mines, Golden, CO.

Taghavi S.A., Marino M.A. and Rolston D.E. (1984) Infiltration from trickle-irrigation source, J. Irrig. Drain. Eng., ASCE, 110(4), 331-341.

Van Genuchten M.T. (1980) A closed form equation for predicting the hydraulic conductivity of unsaturated soils, Soil Sci. Soc. Am. J., 44, 892-898.

Vellidis G. and Smajstrla A.G. (1992) Modeling soil water redistribution and extraction patterns of drip irrigated tomatoes above a shallow water table, Trans ASAE, 35(1), 183-191.

Vrugt J.A., Hopmans J.W. and Šimůnek J. (2001) Calibration of a two-dimensional root water uptake model, Soil Sci. Soc. Am. J., 65, 1027-1037. 